\title{
Reduction of skin water loss in the newborn. II. Clinical trial of two methods in very low birthweight babies
}

\author{
J E H BRICE, N RUTTER, AND D HULL
}

Department of Neonatal Medicine, Nottingham City Hospital, and Department of Child Health, University of Nottingham Medical School

SUMmaRY Two methods of reducing evaporative water and heat loss in the newborn, the thermal blanket and topical paraffin, were compared in a clinical trial. Forty-four babies weighing less than $1.5 \mathrm{~kg}$, nursed in incubators since birth, were either covered with a plastic bubble blanket or had a paraffin mixture applied to their skin at 6- to 8-hour intervals for the first 2 weeks of life. There was no significant difference between the two groups in terms of mortality, morbidity, weight gain or loss, and temperature control. Two babies in the blanket group were removed from the study because of persistently low body temperatures. Five babies in the paraffin group had minor skin rashes and a further 2 had more extensive rashes which led to their removal from the study. Both methods resulted in good temperature control in babies after the first day of life. In the first 24 hours however, neither method of treatment could prevent subnormal body temperatures in the babies weighing less than $1.0 \mathrm{~kg}$, even though the incubator air temperature was on average more than $1^{\circ} \mathrm{C}$ above the rectal temperature. Other methods are necessary to achieve normal body temperatures in these vulnerable babies.

Low body temperatures are commonly found in very small immature babies nursed naked in incubators in the first few days of life. This is mainly the result of high skin water losses. ${ }^{1}$ Low deep body temperatures in preterm babies are associated with an increase in mortality ${ }^{2-5}$ and morbidity. ${ }^{6}$ It is therefore desirable to reduce the skin water losses in the hope that temperature control, survival, and growth may be improved.

Marks et al. ${ }^{7}$ described a method of reducing skin water loss in small babies using a thermal blanket. They reported that babies who were covered with this transparent packaging material showed a mean reduction in insensible weight loss of about $70 \%$. An alternative approach is to apply a waterproofing agent directly to the skin. In the previous paper (page 669) ${ }^{8}$ it was shown that the application of a paraffin mixture to the skin of preterm infants reduced skin water loss by $40-60 \%$ after one application, and that this waterproofing effect lasted for several hours. In this investigation the thermal blanket and paraffin were compared to see if either had any advantage in terms of survival, temperature control, and growth. As it is known that very immature infants have high transepidermal water losses during the first few days of life we did not have a control group.

\section{Methods}

The study was performed during a 9-month period, October 1978 to June 1979, on an unselected group of babies weighing $1.5 \mathrm{~kg}$ or less admitted within 24 hours of delivery to the Department of Neonatal Medicine, City Hospital, Nottingham. The infants were grouped according to their body weight $(500-749,750-999,1000-1249,1250-1500 \mathrm{~g})$ and within each group alternate infants were treated by one or other method. Gestation was assessed according to the method of Dubowitz et al. ${ }^{9}$

Those allocated to the paraffin group had a mixture of $80 \%$ soft paraffin and $20 \%$ hard paraffin BP applied to their whole skin, except face, as soon as possible after admission to the unit. It was then regularly reapplied at 6 - to 8-hour intervals. In the other group the infants were covered with a disposable plastic 'thermal blanket' (Spicer-Cowan bubble pack) soon after admission to the unit. The 
blanket did not cover the baby's head, and as far as possible was kept in place over the baby except for removal during nursing and medical procedures.

Other aspects of management of the two treatment groups were similar, and nursing and medical procedures were performed according to the policies of the unit. Wherever possible a bonnet, socks, mittens, and a disposable napkin were worn but otherwise the babies were nursed naked in standard incubators (79, Vickers Medical) without added humidity. Incubator temperature was regulated by the nursing staff to maintain abdominal skin and rectal temperatures within normal limits. The criteria for intravenous fluid therapy and oral feeding were the same in both groups.

The babies were studied for a period of 2 weeks. The effects of the two treatments were assessed according to mortality, weight lost or gained, fluid requirements, electrolyte balance, and temperature control. This information was obtained from the medical and nursing records. Abdominal skin and incubator temperatures were taken every hour, and rectal temperatures were taken every 3 to 4 hours.

The study received the support of the local hospital ethical committee. Statistical analysis of results was performed using Student's $t$ test.

\section{Subjects}

Forty-four newborn infants were studied. For the purposes of presenting the results the infants have been divided into two weight groups-1.0-1.5, and $<1.0 \mathrm{~kg}$. The mean birthweights and gestations were similar in comparable treatment groups (Table 1). Two infants in the blanket group, of $<1.0 \mathrm{~kg}$ birthweight, were later removed from the study as the blanket appeared to be preventing heat gain. Two infants in the paraffin group with birthweights of $1 \cdot 0-1 \cdot 5 \mathrm{~kg}$ were also taken from the study because of skin rashes.

\section{Results}

There was no difference in mortality between the groups (Table 2). The clinical course was also similar with respect to the incidence of respiratory distress, and the need for oxygen therapy, assisted ventilation, blood transfusion, and intravenous feeding. The body weight changes after birth in the $1.0-1.5 \mathrm{~kg}$ infants were similar in the two treatment groups, $50 \%$ regaining their birthweight by age 2 weeks. In the lower birthweight babies, although on average there was less weight loss after birth in the group treated with paraffin, this was not statistically significant. By age 2 wecks, 2 of the infants in the
Table 1 Details of the 44 babies studied

\begin{tabular}{|c|c|c|c|c|}
\hline & \multicolumn{2}{|c|}{$1.0-1.5 \mathrm{~kg}$} & \multicolumn{2}{|l|}{$<I .0 \mathrm{~kg}$} \\
\hline & $\begin{array}{l}\text { Paraffin } \\
(n=12)\end{array}$ & $\begin{array}{l}\text { Blanket } \\
(n=12)\end{array}$ & $\begin{array}{l}\text { Paraffin } \\
(n=10)\end{array}$ & $\begin{array}{l}\text { Blanket } \\
(n=10)\end{array}$ \\
\hline $\begin{array}{r}\text { Birthweight (kg) } \\
\quad(\text { mean } \pm \text { SD) }\end{array}$ & $\begin{array}{l}1 \cdot 21 \\
\pm 0 \cdot 15\end{array}$ & $\begin{array}{l}1 \cdot 25 \\
\pm 0 \cdot 17\end{array}$ & $\begin{array}{l}0.88 \\
\pm 0 \cdot 12\end{array}$ & $\begin{array}{l}0.86 \\
\pm 0.09\end{array}$ \\
\hline $\begin{array}{c}\text { Gestation (weeks) } \\
\text { (mean } \pm \text { SD) }\end{array}$ & $\begin{array}{l}31 \cdot 8 \\
\pm 2 \cdot 2\end{array}$ & $\begin{array}{l}31 \cdot 2 \\
\pm 2 \cdot 1\end{array}$ & $\begin{array}{l}28 \cdot 4 \\
\pm 2 \cdot 7\end{array}$ & $\begin{array}{l}28 \cdot 0 \\
\pm 1 \cdot 6\end{array}$ \\
\hline
\end{tabular}

Table 2 Mortality and weight loss (or gain) in the first 2 weeks

\begin{tabular}{|c|c|c|c|c|}
\hline & \multicolumn{2}{|c|}{$1.0-1.5 \mathrm{~kg}$} & \multicolumn{2}{|l|}{$<1.0 \mathrm{~kg}$} \\
\hline & $\begin{array}{l}\text { Paraffin } \\
(n=12)\end{array}$ & $\begin{array}{l}\text { Blanket } \\
(n=12)\end{array}$ & $\begin{array}{l}\text { Paraffin } \\
(n=10)\end{array}$ & $\begin{array}{l}\text { Blanket } \\
(n=10)\end{array}$ \\
\hline Deaths & 2 & 2 & 4 & 3 \\
\hline $\begin{array}{l}\text { Weight loss (or gain) } \\
\text { (\% birthweight, } \\
\text { mean } \pm \text { SD) }\end{array}$ & & & & \\
\hline $\begin{array}{l}\text { 1st week } \\
\text { 2nd week }\end{array}$ & $\begin{array}{l}-6 \cdot 5 \\
\pm 6 \cdot 5 \\
\pm 0 \cdot 7 \\
\pm 9 \cdot 7\end{array}$ & $\begin{array}{l}-6 \cdot 7 \\
\pm 5 \cdot 6 \\
-1 \cdot 5 \\
\pm 8 \cdot 4\end{array}$ & $\begin{array}{l}-6 \cdot 9 \\
\pm 5 \cdot 7 \\
-2 \cdot 1 \\
\pm 7 \cdot 3\end{array}$ & $\begin{array}{r}-13 \cdot 2 \\
\pm 6 \cdot 6 \\
-7 \cdot 2 \\
\pm 7 \cdot 8\end{array}$ \\
\hline
\end{tabular}

No statistically significant differences between treatment groups.

paraffin-treated group had regained their birthweight, but none had done so in the blanket group. Measurements of fluid intake, plasma electrolytes and urea, haemoglobin, and packed cell volume were similar in comparable treatment groups.

In the infants weighing $1.0-1.5 \mathrm{~kg}$ the rectal, skin, and incubator temperatures during the 2-week period did not differ significantly between the two treatment groups (Table 3). On the day of birth they were nursed in a mean incubator temperature just below the skin and rectal temperatures. During the first week the $T_{R}-T_{A}$ difference increased to $1 \cdot 3$ and $1.4^{\circ} \mathrm{C}$ and during the second week to 2.0 and $2.8^{\circ} \mathrm{C}$ in the paraffin and blanket groups respectively. In the babies of less than $1.0 \mathrm{~kg}$ birthweight, rectal, skin, and incubator temperatures again did not differ significantly between the two treatment groups, although the incubator temperature was consistently slightly lower in the paraffin-treated babies. On the day of birth both treatment groups were nursed in ambient incubator temperatures on average $1.3^{\circ} \mathrm{C}$ above the mean rectal temperature which was still below $36^{\circ} \mathrm{C}$. During the first week the $T_{R}-T_{A}$ difference was $+0.5^{\circ} \mathrm{C}$ and $-0.3^{\circ} \mathrm{C}$ in the paraffinand blanket-treated groups respectively. During the second week the $T_{R}-T_{A}$ difference was $+1 \cdot 6^{\circ} \mathrm{C}$ and $+1 \cdot 2^{\circ} \mathrm{C}$, similar to the larger infants in the first week of life. 
Table 3 Mean ambient incubator temperatures $\left(T_{A}\right)$, abdominal skin temperatures $\left(T_{S}\right)$, and rectal temperatures $\left(T_{R}\right)$ in the first 2 weeks

\begin{tabular}{|c|c|c|c|c|c|}
\hline & & \multicolumn{2}{|l|}{$1.0-1.5 \mathrm{~kg}$} & \multicolumn{2}{|l|}{$<1.0 \mathrm{~kg}$} \\
\hline & & Paraffin & Blanket & Paraffin & Blanket \\
\hline Day 1 (mean $\left.\pm \mathrm{SD}^{\circ} \mathrm{C}\right)$ & $\begin{array}{l}T_{A} \\
T_{S} \\
T_{R}\end{array}$ & $\begin{array}{l}36 \cdot 2 \pm 1 \cdot 1 \\
36 \cdot 7 \pm 0 \cdot 1 \\
36 \cdot 5 \pm 0 \cdot 4\end{array}$ & $\begin{array}{l}35 \cdot 9 \pm 1 \cdot 0 \\
36 \cdot 5 \pm 0 \cdot 5 \\
36 \cdot 4 \pm 0 \cdot 7\end{array}$ & $\begin{array}{l}36 \cdot 9 \pm 1 \cdot 0 \\
36 \cdot 2 \pm 0 \cdot 6 \\
35 \cdot 6 \pm 0.8\end{array}$ & $\begin{array}{l}37 \cdot 3 \pm 0.7 \\
36 \cdot 3 \pm 0.8 \\
35 \cdot 9 \pm 0.6\end{array}$ \\
\hline Days 1-7 & $\begin{array}{l}\mathbf{T}_{\mathbf{A}} \\
\mathbf{T}_{\mathbf{S}} \\
\mathbf{T}_{\mathbf{R}}\end{array}$ & $\begin{array}{l}35 \cdot 5 \pm 1 \cdot 0 \\
36 \cdot 8 \pm 0 \cdot 1 \\
36 \cdot 8 \pm 0 \cdot 4\end{array}$ & $\begin{array}{l}35 \cdot 4 \pm 1 \cdot 0 \\
36 \cdot 8 \pm 0 \cdot 1 \\
36 \cdot 8 \pm 0 \cdot 2\end{array}$ & $\begin{array}{l}36 \cdot 2 \pm 0 \cdot 5 \\
36 \cdot 9 \pm 0 \cdot 3 \\
36 \cdot 7 \pm 0 \cdot 2\end{array}$ & $\begin{array}{l}36 \cdot 8 \pm 0 \cdot 5 \\
36 \cdot 7 \pm 0 \cdot 5 \\
36 \cdot 5 \pm 0 \cdot 6\end{array}$ \\
\hline Days 8-14 & $\begin{array}{l}\mathbf{T}_{\mathbf{A}} \\
\mathbf{T}_{\mathbf{S}} \\
\mathbf{T}_{\mathbf{R}}\end{array}$ & $\begin{array}{l}35 \cdot 0 \pm 0 \cdot 8 \\
36 \cdot 8 \pm 0 \cdot 2 \\
37 \cdot 0 \pm 0 \cdot 1\end{array}$ & $\begin{array}{l}34 \cdot 2 \pm 0 \cdot 8 \\
36 \cdot 9 \pm 0 \cdot 2 \\
37 \cdot 0 \pm 0 \cdot 1\end{array}$ & $\begin{array}{l}35.4 \pm 0.4 \\
37.0 \pm 0.1 \\
37.0 \pm 0.2\end{array}$ & $\begin{array}{l}35 \cdot 7 \pm 0 \cdot 9 \\
37 \cdot 0 \pm 0 \cdot 1 \\
36 \cdot 9 \pm 0 \cdot 1\end{array}$ \\
\hline
\end{tabular}

No statistically significant differences between treatment groups.

\section{Discussion}

We could find no difference between the two treatment groups in terms of mortality, morbidity, weight loss or gain, or temperature control. The plastic thermal blanket is simple to use, safe, and cheap. It acts as a thermal insulator as well as reducing water loss. This may be an advantage to a baby with a normal body temperature but it may prevent an already cold baby from warming up. Two babies had to be withdrawn from the study because the blanket was keeping them cold. When the blanket was removed and topical paraffin applied, the rectal temperature quickly rose. Other disadvantages of the blanket are that it makes observation of the baby difficult and that it has to be removed every time a doctor or nurse requires access to the baby. Topical paraffin does not interfere with observation of the baby and allows access. However, the baby is disturbed during its application. It caused minor skin rashes in 5 babies and in 2 others the rashes were sufficiently extensive to cause them to be removed from the study. The rashes were blotchy, erythematous, and of the heat rash type. As far as we could determine they were not due to infection of the skin.

Both methods of treatment provided good temperature control except in babies of less than $1.0 \mathrm{~kg}$ on the first day of life. These babies had subnormal rectal temperatures although the mean air temperature was more than $1^{\circ} \mathrm{C}$ higher than the mean rectal temperature. This suggests that neither the thermal blanket nor the paraffin was able to prevent the high evaporative water and heat losses which occur when very small, immature babies are nursed in unhumidified incubators soon after birth. In order to prevent the body temperature of these babies from falling to subnormal levels, other methods have to be used.

The thermal blanket and the application of paraffin are both suitable methods of reducing evaporative water loss when babies of low birthweight are nursed naked in incubators. Other methods need to be explored for overcoming the very high evaporative heat losses of the smallest, most immature babies on the critical first day of life.

We thank the nursing staff of the Department of Neonatal Medicine, Nottingham City Hospital, for help with this study.

\section{References}

1 Rutter N, Hull D. Water loss from the skin of term and preterm babies. Arch Dis Child 1979; 54: 858-68.

2 Silverman W A, Fertig J W, Berger A P. The influence of the thermal environment upon the survival of newly-born premature infants. Pediatrics 1958; 22: 876-86.

3 Jolly H, Molyneux P, Newell D J. A controlled study of the effect of temperature on premature babies. $J$ Pediatr 1962; 60: 889-94.

4 Day R L, Caliguiri L, Kamenski C, Ehrlich F. Body temperature and survival of premature infants. Pediatrics 1964; 34 : 171-81.

5 Buetow K C, Klein S W. Effect of maintenance of 'normal' skin temperature on survival of infants of low birthweight. Pediatrics 1964; 34: 163-70.

- Davies P A, Tizard J P M. Very low birthweight and subsequent neurological deficit. Dev Med Child Neurol 1975; 17: 3-17.

7 Marks K H, Friedman Z, Maisels M J. A simple device for reducing insensible water loss in low birthweight infants. Pediatrics 1977; 60: 223-6.

8 Rutter N, Hull D. Reduction of skin water loss in the newborn. I. Effect of applying topical agents. Arch Dis Child 1981; 56: 669-72.

- Dubowitz L M S, Dubowitz V, Goldberg C. Clinical assessment of gestational age in the newborn infant. J Pediatr 1970; 77: 1-10.

Correspondence to Dr N Rutter, Department of Child Health, Medical School, Queen's Medical Centre, Clifton Boulevard, Nottingham NG7 2UH.

Received 22 July 1980 